\title{
PENGARUH EFEKTIVAS PENGELOLAAN DANA DESA TERHADAP PEMBERDAYAAN MASYARAKAT DI KECAMATAN TELUKNAGA KABUPATEN TANGERANG
} (Studi Kasus pada Desa Babakan Asem, Desa Keboncau, Desa Kampung Melayu Timur) Siti Wahyuni Ramadhani ${ }^{1}$, H. Achmad Murodi, Drs.,MM², Hari Muljono, Drs., MBA ${ }^{3}$

Jurusan Ilmu Administrasi Negara, Fakultas Ilmu Sosial dan Ilmu Politik

\author{
Universitas Islam Syekh Yusuf Tangerang \\ E-mail : ayu.ramadhani1998@gmail.com
}

\begin{abstract}
The title of this thesis is "The Influence of Effectiveness of Village Fund Management of Community Empowerment in Teluknaga sub-district of Tangerang Regency". The method used in this research is a quantitative method. In determining the sample size of researchers using the technique of Quota Sampling (Sugiyono 2016: 85). Where the technique used to determine samples from populations that have certain characteristics to the desired amount. The samples are the community that has the characteristics of following a community empowerment program held in each village where they live which is located in three villages in the sub-district of Teluknaga Tangerang Regency. In the data collection, the research uses the dissemination of adoptive instruments, interview and observations. The analysis technique used in this research is quantitative analysis method is research conducted by collecting answers from respondents or questions that are the measurements of the variables studied. Then the data obtained were analyzed using SPSS (Statistical Product and Solution Services) for windows version 24 using correlation techniques using the method person product moment according to Sugiyono and continued regression testing.
\end{abstract}

Keywords : Effectiveness, Village Fund, Community Empowerment

Abstrak : Judul skripsi ialah "Pengaruh Efektivitas Pengelolaan Dana Desa Terhadap Pemberdayaan Masyarakat Di Kecamatan Teluknaga Kabupaten Tangerang”. Metode yang digunakan dalam penelitian ini adalah metode Kuantitatif asosiatif. Dalam menentukan ukuran sampel peneliti menggunakan Sampling Kuota (Sugiyono 2016 : 85). Dimana teknik yang digunakan untuk menentukan sampel dari populasi yang mempunyai ciri-ciri tertentu sampai jumlah yang diinginkan. Adapun yang dijadikan sampel adalah masyarakat yang memiliki ciri mengikuti program pemberdayaan masyarakat yang diadakan pada masing-masing desa di tempat tinggalnya yang berada di tiga desa di lingkungan Kecamatan Teluknaga Kabupaten Tangerang. Dalam pengambilan data, peneliti menggunakan instrumen penyebaran angket, hasil wawancara dan pengamatan. Adapun teknik analisa yang digunakan dalam penelitian ini adalah analisis kuantitatif yaitu merupakan penelitian yang dilakukan dengan mengumpulkan jawaban dari responden atau pertanyaan yang merupakan pengukuran dari variabel yang diteliti. Kemudian data yang diperoleh dalam penelitian dianalisis menggunakan SPSS (Statistical Product and Solution Services) for Windows versi 24 dengan menggunakan teknik korelasi dan metode Person Product Moment serta dilanjutkan dengan pengujian regresi.

Kata Kunci : Efektivitas, Dana Desa, Pemberdayaan Masyarakat 


\section{PENDAHULUAN}

Untuk menjalankan kewenangannya, pemerintah desa memiliki sumber-sumber penerimaan yang digunakan untuk membiayai kegiatan-kegiatan yang tertulis di Rancangan Anggaran Belanja Desa. Menurut Peraturan Pemerintah Dalam Negeri Tahun 2014 salah satu sumber penerimaan desa yaitu dana desa. Berdasarkan Peraturan Pemerintah Republik Indonesia Nomor 60 Tahun 2014 pasal 1 ayat 2 tentang Dana Desa yang berisi: Dana Desa adalah dana yang bersumber dari APBN yang diperuntukan bagi Desa yang ditransfer melalui APBD kabupaten/kota dan digunakan untuk membiayai penyelenggaraan pemerintahan, pelaksanaan pembangunan, pembinaan kemasyarakatan, dan pemberdayaan masyarakat.

Pengalokasian dana desa berdasarkan Direktorat Jenderal Perimbangan Keuangan melaksanakan perhitungan rincian Dana Desa bagi setiap wilayah Kabupaten/ Kota secara kesamarataan yang didasarkan kepada dua macam alokasi. Pertama alokasi dasar sebesar 90\%, kedua dihitung berdasarkan jumlah Desa dan jumlah penduduk, angka kemiskinan, luas wilayah dan tingkat kesulitan geografis. Dengan bergulirnya dana desa harus menciptakan desa yang sejahtera, untuk itu semestinya proses perubahan ke arah Pemberdayaan Masyarakat harus secara optimal, karena pemberdayaan

\section{TINJAUAN PUSTAKA}

\section{Efektivitas}

Secara etimologi kata efektivitas berasal dari kata efektif. Dalam Kamus Besar Bahasa Indonesia, efektivitas didefinisikan seperti sesuatu yang ada akibat atau pengaruhnya dapat membawa hasil berhasil bagi (tindakan) serta dapat pula berarti mulai berlaku (tentang undang-undang/ peraturan). Menurut Dunn (2000:429) efektivitas (effectiveness) berkenaan dengan apakah suatu pilihan mencapai hasil masyarakat merupakan aset pembangunan ekonomi yang berupaya memperbaiki pendidikan masyarakat, aksesibilitas, tindakan, kelembagaan, bisnis, meningkatkan pendapatan dan lainnya yang dapat meningkatkan harkat dan martabat lapisan masyarakat yang dalam kondisi sekarang tidak mampu untuk melepaskan diri dari perangkap kemiskinan dan keterbelakangan.

Pentingnya pemberdayaan masyarakat menuntut setiap aparatur desa bersikap bijak dalam pengelolaan dana desa agar anggaran tersebut dapat bersifat efektif, hal ini sesuai dengan pedoman Pengelolaan Keuangan Negara pada UU Nomor 17 Tahun 2003 Pasal 3 ayat 1 tentang Keuangan Negara yang berisi: "Keuangan Negara dikelola secara tertib, taat pada peraturan perundang-undangan, efisien, ekonomis, efektif, transparan, dan bertanggung jawab dengan memperhatikan rasa keadilan", apabila anggaran tersebut dikelola secara baik maka hasil kegiatan otonomi desa, khususnya pemberdaayaan masyarakat akan terlihat jelas begitupun sebaliknya jika anggaran tersebut dikelola dengan tidak baik, maka tidak jelas kegiatan dan output (hasil kegiatan) yang efisien dan efektif yang berkaitan dengan pemberdayaan masyarakat ataupun infrastruktur.

(akibat) yang diharapkan, atau mencapai tujuan dan diadakannya tindakan.

\section{Dana Desa}

Menurut Buku Pintar Dana Desa (2017: 22) Dana desa adalah dana yang berasal dari Anggaran Pendapatan dan Belanja Negara (APBN) yang diberikan kepada Desa yang ditransfer melalui Anggaran Pendapatan Belanja Daerah (APBD) kabupaten/ kota dan diutamakan untuk pelaksanaan pembangunan dan pemberdayaan 
masyarakat. Dana desa yang diberikan kepada desa dihitung berdasarkan jumlah Desa dengan memperhatikan jumlah penduduk, angka kemiskinan, luas wilayah, tingkat kesulitan geografis.

\section{Pengelolaan}

Pengelolaan berawal dari kata kelola, dalam Kamus Besar Bahasa Indonesia Kontemporer karangan Peter Salim dan Yenny Salim (2002: 695), berarti memimpin, mendendalikan, mengatur, dan mengusahakan agar lebih baik, lebih maju dan sebagainya juga bertanggung jawab atas pekerjaan tertentu.

\section{Pemberdayaan Masyarakat}

Pemberdayaan berasal dari bahasa Inggris "empowerment" yang dimaknai sebagai pemberkuasaan. Dalam arti pemberian ataupun peningkatan "kekuasaan" (power) kepada masyarakat yang lemah ataupun belum

\section{Metode Penelitian}

Menurut Sugiyono (2014: 1) mengemukakan "Metode penelitian pada dasarnya merupakan cara ilmiah untuk mendapatkan data dengan tujuan dan kegunaan tertentu". Dalam penelitian ini, metode yang digunakan adalah metode penelitian kuantitatif penelitian bertujuan untuk mengetahui hubungan antara dua variabel lebih. Menurut Sugiyono (2016 : 11), "Metode kuantitatif merupakan penelitian berupa angkaangka dan analisis menggunakan statistik.

Dalam penelitian ini yang menjadi

variabel penelitian adalah:

1. Variabel bebas atau independent $(\mathrm{X})$

Variabel bebas adalah variabel yang mempengaruhi atau yang menjadi sebab perubahannya atau timbulnya variabel dependen (terikat) dalam penelitian ini variabel $\mathrm{X}$ yaitu Efektivitas Pengelolaan Dana Desa indikatornya yaitu:

a) Perencanaan beruntung. Menurut Totok dan Poerwoko (2017: 100) bahwa pemberdayaan masyarakat menjadi salah satu fokus utama dari pembangunan, pembangunan fisik juga harus dibarengi dengan pembangunan nonfisik. Menjadi sebuah tantangan besar dalam memberdayakan masyarakat desa yang dipandang marjinal. Pemberdayaan berasal dari kata "daya" yang diartikan suatu kemampuan atau kekuatan. Bertolak dari pengertian tersebut, oleh karena itu pemberdayaan dapat diberikan pengertian sebagai suatu proses menuju berdaya.

Sedangkan menurut Subejo dan Supriyanto (2005) yang dikutip Poerwoko (2017: 45) :

Pemberdayaan masyarakat memiliki keterkaitan erat dengan sustainable development dimana pemberdayaan masyarakat merupakan suatu prasyarat utama serta dapat diibaratkan sebagai gerbong yang akan membawa masyarakat menuju suatu keberlanjutan secara ekonomi, sosial dan ekologi yang dinamis.

b) Pelaksanaan

c) Penatausahaan

d) Pelaporan

e) Pertanggungjawaban

2. Variabel terikat atau dependen (Y)

Variabel terikat merupakan suatu variabel yang dipengaruhi atau yang menjadi akibat karena adanya variabel bebas. Variabel terikat atau dependen dalam penelitian ini yaitu Pemberdayaan Masyarakat (Y) adalah hasil yang dapat dicapai oleh seseorang atau sekelompok orang dalam suatu instansi sesuai dengan wewenang dan tanggung jawab masingmasing dalam rangka upaya mencapai tujuan yang ditetapkan. Adapun indikator Pemberdayaan Masyarakat sebagai berikut:

a) Kebebasan mobilitas

b) Kemampuan membeli komoditas kecil

c) Kemampuan membeli komoditas besar 
d) Terlibat dalam pembuatan keputusan rumah tangga

e) Kebebasan relatif dari dominasi keluarga

f) Kesadaran hukum dan politik

g) Keterlibatan dalam kampanye protes-protes

h) Jaminan ekonomi dan kontribusi terhadap keluarga

\section{Populasi}

Menurut Sugiyono (2016: 119) bahwa: "Populasi adalah wilayah generalisasi yang terdiri atas: objek/subjek yang mempunyai kuantitas dan karakteristik tertentu yang ditetapkan oleh peneliti untuk dipelajari dan kemudian ditarik kesimpulannya”.

Berdasarkan pengertian diatas tersebut, maka populasi dalam penelitian ini di ambil dari 3 Desa di Kecamatan Teluknaga .

\section{Hasil Penelitian}

Hasil penelitian yang peneliti dapatkan berasal dari kuesioner yang disebarkan ke responden sebanyak 100 orang, setelah mendapatkan jawaban dari responden dilakukan pengujian data menggunakan SPPS versi 24 menghasilkan data sebagai berikut :

\section{Perbandingan antara $r$ hitung dengan $r$ tabel}

\section{Variabel X}

\begin{tabular}{|c|c|c|c|c|}
\hline $\begin{array}{c}\text { No } \\
(\mathrm{X})\end{array}$ & $\mathrm{r}$ hitung & $\mathrm{r}$ tabel & Hasil & Keterangan \\
\hline 1 & 0.388 & 0.199 & r.hitung>r.tabel & Valid \\
\hline 2 & 0.636 & 0.199 & r.hitung>r.tabel & Valid \\
\hline 3 & 0.382 & 0.199 & r.hitung>r.tabel & Valid \\
\hline 4 & 0.528 & 0.199 & r.hitung>r.tabel & Valid \\
\hline 5 & 0.445 & 0.199 & r.hitung>r.tabel & Valid \\
\hline
\end{tabular}

\section{Sampel}

Menurut Sugiyono (2016: 85) sampling kuota adalah teknik untuk menentukan sampel dari populasi yang mempunyai ciri-ciri tertentu sampai jumlah (kuota) yang diinginkan. Sampel dalam penelitian ini yaitu masyarakat di tiga desa di Kecamatan Teluknaga yaitu Desa Babakan Asem, Desa Kebon Cau, dan Desa Kampung Melayu Timur.

Oleh karena itu peneliti menentukan kuota sebesar 100 orang, artinya sampel dalam penelitian ini berjumlah 100 orang, dimana 100 orang yang terdiri dari 30 orang masyarakat desa babakan asem, 30 masyarakat desa kebon cau, 40 masyarakat desa kampung melayu timur dimana sampel yang akan diambil dari masingmasing desa tersebut masyarakat yang memiliki ciri mengikuti kegiatan pemberdayaan masyarakat di desa tersebut.

\section{Perbandingan antara $r$ hitung dengan $r$ tabel} Variabel Y

\begin{tabular}{|c|c|c|c|c|}
\hline $\begin{array}{c}\text { No } \\
(Y)\end{array}$ & $\begin{array}{c}\text { r } \\
\text { hitung }\end{array}$ & $\begin{array}{c}\text { r } \\
\text { tabel }\end{array}$ & Hasil & Keterangan \\
\hline 1 & 0.372 & 0.199 & r.hitung>r.tabel & Valid \\
\hline 2 & 0.269 & 0.199 & r.hitung>r.tabel & Valid \\
\hline 3 & 0.430 & 0.199 & r.hitung>r.tabel & Valid \\
\hline 4 & 0.474 & 0.199 & r.hitung>r.tabel & Valid \\
\hline 5 & 0.389 & 0.199 & r.hitung>r.tabel & Valid \\
\hline 6 & 0.469 & 0.199 & r.hitung>r.tabel & Valid \\
\hline 7 & 0.499 & 0.199 & r.hitung>r.tabel & Valid \\
\hline 8 & 0.394 & 0.199 & r.hitung>r.tabel & Valid \\
\hline
\end{tabular}

\section{Correlations}

\begin{tabular}{|c|c|c|c|}
\hline & & $\begin{array}{l}\text { Variabel_X_Ef } \\
\text { ektivitas_ } \\
\text { Pengelolaan_ } \\
\text { Dana_Desa }\end{array}$ & $\begin{array}{c}\text { Variabel_Y_ } \\
\text { Pemberdayaan_Ma } \\
\text { syarakat }\end{array}$ \\
\hline \multirow{3}{*}{$\begin{array}{l}\text { Variabel_ } \\
\text { X_Efektivi } \\
\text { tas_Peng } \\
\text { elolaan_D } \\
\text { ana_Desa }\end{array}$} & $\begin{array}{l}\text { Pearson } \\
\text { Correlation }\end{array}$ & 1 & $.587^{* *}$ \\
\hline & $\begin{array}{l}\text { Sig. (2- } \\
\text { tailed) }\end{array}$ & & 0.000 \\
\hline & $\mathrm{N}$ & 100 & 100 \\
\hline \multirow{3}{*}{$\begin{array}{l}\text { Variabel_ } \\
\text { Y_Pembe } \\
\text { rdayaan_- } \\
\text { Masyarak } \\
\text { at }\end{array}$} & $\begin{array}{l}\text { Pearson } \\
\text { Correlation }\end{array}$ & $.587^{* *}$ & 1 \\
\hline & $\begin{array}{l}\text { Sig. (2- } \\
\text { tailed) }\end{array}$ & 0.000 & \\
\hline & $\mathrm{N}$ & 100 & 100 \\
\hline
\end{tabular}




\begin{tabular}{|c|c|c|c|c|}
\hline \multicolumn{5}{|c|}{ Model Summary } \\
\hline Model & $\mathrm{R}$ & R Square & $\begin{array}{l}\text { Adjusted R } \\
\text { Square }\end{array}$ & $\begin{array}{l}\text { Std. Error of } \\
\text { the Estimate }\end{array}$ \\
\hline 1 & $.587^{\mathrm{a}}$ & 0.344 & 0.337 & 2.453 \\
\hline
\end{tabular}

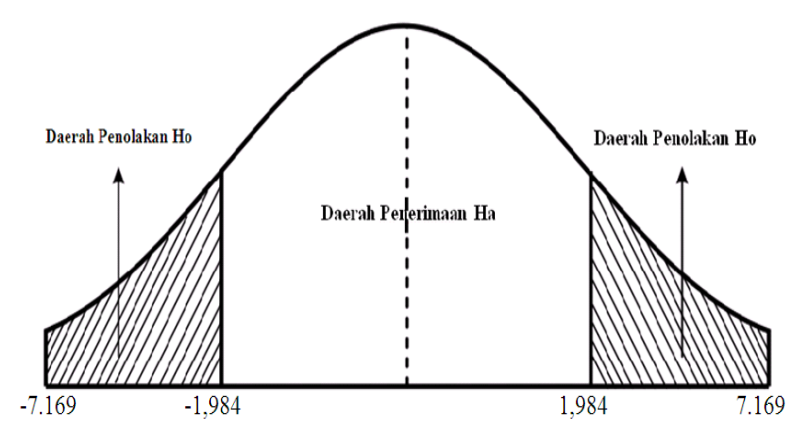

1. Efektivitas Pengelolaan Dana Desa di Kecamatan Teluknaga Kabupaten Tangerang sebesar $73 \%$ memenuhi kriteria yang ditetapkan.

2. Pemberdayaan Masyarakat di Kecamatan Teluknaga Kabupaten Tangerang dengan hasil penelitian yaitu sebesar $75 \%$ dari kriteria yang ditetapkan.

3. Pengaruh Efektivitas Pengelolaan Dana Desa terhadap Pemberdayaan Masyarakat sebesar

\section{Kesimpulan}

Berdasarkan uraian pada bab IV, peneliti akan menarik kesimpulan atas pembahasan Pengaruh Efektivitas Pengelolaan Dana Desa Terhadap Pemberdayaan Masyarakat di Kecamatan Teluknaga Kabupaten Tangerang, dapat ditarik kesimpulan sebagai berikut:

1. Pelaksanaan Efektivitas Pengelolaan Dana

Desa di Kecamatan Teluknaga

Kabupaten Tangerang yaitu sebesar 73\% dari kriteria yang diterapkan

2. Pelaksanaan Pemberdayaan Masyarakat di Kecamatan Teluknaga Kabupaten

Tangerang yaitu sebesar $75 \%$ dari kriteria yang diterapkan.

3. Terdapat hubungan yang sedang antara variabel Efektivitas Pengelolaan Dana Desa terhadap Pemberdayaan Masyarakat di Kecamatan Teluknaga Kabupaten Tangerang yang
0.587. Jika diinterprestasikan menurut Sugiyono (2017: 184) bahwa interval koefisien korelasi 0,40-0,599 masuk dalam kategori "Sedang".

4. Koefisien Determinasi (KD) adalah sebesar 0,344 atau $34,4 \%$. Dengan demikian Pengaruh Efektivitas Pengelolaan Dana Desa di Kecamatan Teluknaga Kabupaten Tangerang $34,4 \%$ dan sebesar $65,6 \%$ dipengaruhi variabel-variabel lain.

5. Koefisien korelasi Efektivitas Pengelolaan Dana Desa Terhadap Pemberdayaan Masyarakat diperoleh nilai $t_{\text {hitung }}$ sebesar 7,169 diperbandingakan dengan $t_{\text {tabel }}$ 1,984 maka 7,169 > 1,984. Jadi Ho ditolak dan Ha diterima artinya hipotesis yang peneliti kemukakan :

“Terdapat Pengaruh Positif Dan Signifikan Antara Efektivitas Pengelolaan Dana Desa Terhadap Pemberdayaan Masyarakat di Kecamatan Teluknaga Kabupaten Tangerang”, terbukti kebenarannya.

ditunjukan dengan koefisien korelasi sebesar 0,587 atau $58,7 \%$. Sedangkan koefisien determinasi (KD) adalah 0,344 atau 34,4\%. Dengan demikian efektivitas pengelolaan dana desa memberikan pengaruh terhadap pemberdayaan masyarakat sebesar $34,4 \%$ dan $65,6 \%$ masih dipengaruhi oleh faktor lain.

\section{Saran}

1. Mengingat efektivitas pengelolaan dana desa berpengaruh terhadap pemberdayaan masyarakat, untuk itu perlu adanya upayaupaya untuk lebih meningkatkan efektivitas pengelolaan dana desa.Dalam meningkatkan pemberdayaan masyarakat sehingga kehidupan masyarakat dapat lebih bisa mandiri dan berkualitas. 
2. Kepala desa sebaiknya memberikan evaluasi disetiap pengeluaran dan penerimaan guna untuk peningkatan efektivitas pengelolaan dana desa untuk berjalan dengan lancarnya pemberdayaan masyarakat, agar tercapainya visi desa tersebut.

3. Untuk memperlancar tugas setiap bagian diperlukan adanya pendidikan dan pelatihan khususnya dalam IMTAQ (Iman dan Taqwa) dan IPTEK (Ilmu Pengetahuan dan
Teknologi agar pegawai lebih meningkatkan moralitas dan kualitasnya.

4. Kepala desa lebih selektif dalam memilih pegawai perlu diadakannya interview dan ujian terlebih dahulu agar pegawai bekerja sesuai dengan komptensinya dan bekerja dengan giat.

5. Kepala Desa memberikan motivasi kepada masyarakat yang belum ingin berpartisipasi dalam program pemberdayaan masyarakat.

\section{Daftar Pustaka}

Adisasmita, Rahardjo. 2013. Pembangunan Perdesaan: Pendekatan Partisipatif, Tipologi, Strategi, Konsep Desa Pusat Pertumbuhan. Yogyakarta: Graha Ilmu

Anggara, Sahya. 2016. Ilmu Administrasi Negara. Cetakan Kedua. Bandung: CV Pustaka Setia

Feriyanto, Andri dan Triana ES. 2015. Pengantar Manajemen (3 in 1). Kebumen: Mediatera

Karimah, Saleh, dan Wanusmawatie. 2014. Pengelolaan Alokasi Dana Desa Dalam Pemberdayaan Masyarakat (Studi pada Desa Deket Kulon Kecamatan Deket Kabupaten Lamongan). Jurnal Administrasi Publik. Vol 2 (4): 597-602.

Kementrian Keuangan Republik Indonesia. 2017. Buku Pintar Dana Desa dengan tema "Dana Desa Untuk Kesejahteraan Masyarakat: Menciptakan Lapangan Kerja, Mengatasi Kesenjangan dan Mengentaskan Kemiskinan. Jakarta: Menteri Keuangan

Makmur. 2015. Filsafat Administrasi. Jakarta: Bumi Aksara

Mardikanto, Totok dan Soebianto Poerwoko. 2017. Pemberdayaan Masyarakat Dalam Perspektif Kebijakan Publik. Bandung: Alfabeta.

Novelya S, Tinangon., dan Rondonuwu. 2016. Pengukuran Efisiensi dan Efektivitas Pengelolaan Keuangan Daerah Pada Dinas Pengelola Keuangan, Pendapatan dan Aset (DPKPA) Kabupaten Minahasa Selatan. Manado: Universitas Sam Ratulangi 